\title{
Articles
}

\section{Macrosomia despite good glycaemic control in Type I diabetic pregnancy; results of a nationwide study in The Netherlands}

\author{
I. M. Evers ${ }^{1}$, H. W. de Valk ${ }^{2}$, B. W. J. Mol ${ }^{1}$, E. W. M. T. ter Braak ${ }^{2}$, G. H. A. Visser ${ }^{1}$ \\ ${ }^{1}$ Department of Obstetrics, ${ }^{2}$ Department of Internal Medicine and Endocrinology, University Medical Centre, Utrecht, The Netherlands
}

\begin{abstract}
Aims/hypothesis. To investigate the incidence of foetal macrosomia (i.e. birth weight $>90$ th percentile) in a nonselected nationwide cohort of women with Type I (insulin-dependent) diabetes mellitus in The Netherlands and to identify risk indicators predictive for macrosomia.

Methods. We conducted a prospective nationwide cohort based survey regarding the outcome of Type I diabetic pregnancy in The Netherlands. Data of 289 women who gave birth to a live singleton infant without major congenital malformations at more than or equal to 28 weeks of gestation are shown.

Results. The incidence of foetal macrosomia was very high $(48.8 \%$ ), with $26.6 \%$ of infants weighing more than 97.7th percentile. Glycaemic control during pregnancy was good (i.e. mean $\mathrm{HbA}_{1 \mathrm{c}} \leq 7.0 \%$ ), in almost all (84\%) women. Multiple logistic regression analysis resulted in a predictive model for macrosomia that incorporated five variables: third trimester $\mathrm{HbA}_{1 \mathrm{c}}$ (Odds Ratio [95\% Con-
\end{abstract}

fidence Interval]: (1.6[1.1-2.4]), absence of third trimester severe hypoglycaemia (3.0[1.2-7.3]), the use of insulin lispro (3.1[0.9-10.4]), weight gain during pregnancy (1.1[1.0-1.2]) and non-smoking (2.8[0.9-9.3]). Third trimester $\mathrm{HbA}_{1 \mathrm{c}}$ was the most powerful predictor for the occurrence of macrosomia, but its predictive capacity was weak (explained variance $<5 \%$ ).

Conclusion/interpretation. Despite apparent good glycaemic control, the incidence of foetal macrosomia in this non-selected prospective nationwide cohort of 289 Type I diabetic women was very high. Third trimester $\mathrm{HbA}_{1 \mathrm{c}}$ was the most powerful predictor, but its predictive capacity was weak. Thus, future research should focus on new more detailed glucose monitoring techniques (such as a continuous glucose monitoring system) as well as to alternative factors to reduce macrosomia. [Diabetologia (2002) 45:1484-1489]

Keywords Macrosomia, glycaemic control, diabetes mellitus, Type I diabetes, pregnancy.
Prevention of foetal macrosomia in pregnancies with Type I (insulin-dependent) diabetes mellitus would reduce serious perinatal morbidity and mortality. Mac-

Received: 26 April 2002 / Revised: 8 July 2002

Published online: 25 September 2002

(C) Springer-Verlag 2002

Corresponding author: I. M. Evers, MD, Department of Obstetrics (Room:KE4.134.1), University Medical Centre Utrecht, P.O. Box 85090, 3508 AB Utrecht, The Netherlands.

E-mail: ingwil@worldonline.nl

Abbreviations: CGMS, Continuous glucose monitoring system; CSII, continuous subcutaneous insulin infusion; MIT, multiple injection treatment; OR, odds ratio; $\mathrm{SH}$, severe hypoglycaemia; SMBG, self-monitoring of blood glucose. rosomia is related to an increased risk for "unexplained" death in utero and shoulder dystocia during labour, the latter being related to asphyxia, clavicle fracture and/or Erbs palsy [1, 2, 3]. During the neonatal period macrosomic infants are at increased risk for hypoglycaemia, infant respiratory distress syndrome (IRDS), hyperbilirubinaemia and hypertrophic cardiomyopathy $[4,5,6]$. A number of long-term population studies have shown that macrosomic newborns of women with diabetes have a higher risk to develop obesity and Type II (non-insulin-dependent) diabetes mellitus at a young age $[7,8,9]$.

Foetal growth depends on foetal, placental and maternal factors. Determinants affecting foetal growth are genetic factors, fetal hormones (insulin, insulin- 
like growth factors), uterine constraints (placental functioning, substrate flow) and maternal factors (parity, smoking, obesity, height, weight gain in pregnancy, prolonged pregnancy) [10]. Maternal diabetes is associated with abnormal - excessive - fetal growth. Hyperglycaemia is considered a determinant of excessive foetal growth, although the relationship between glycaemic control during pregnancy and the occurrence of macrosomia is lower than might be expected. Differences in $\mathrm{HbA}_{1 \mathrm{c}}$ explained only 6 to $23 \%$ of the variance in birth weight $[5,11,12]$, whereas $1 \mathrm{~h}$ postprandial blood glucose values predicted $28.5 \%$ of the macrosomic infants born to diabetic mothers [13]. This relatively weak relationship could be due to the use of inadequate markers of (overall) glycaemic control or due to other yet unknown factors.

However, despite improved glycaemic control over the past decade, the incidence of macrosomia is still very high $(27-43 \%)$ and does not seem to decline [1, $4,5,14,15,16,17]$. When trying to reduce macrosomia in Type I diabetic pregnancies, it would be useful to know the characteristics of women with the highest risk for having a macrosomic infant.

We assessed the incidence of macrosomia in a nonselected prospective nationwide cohort based study of pregnant Type I diabetic women in The Netherlands and investigated the clinical characteristics of the women who gave birth to a macrosomic infant.

\section{Subjects and methods}

All gynaecologists, internists and diabetes nurse educators in The Netherlands were asked to include all Type I diabetic women presenting themselves for antenatal care, between $1^{\text {st }}$ April 1999 and $1^{\text {st }}$ April 2000, in a cohort based survey regarding the outcome of Type I diabetic pregnancy in The Netherlands. Eligible pregnant women were asked to fill out sets of questionnaires at inclusion (at $\sim 10$ weeks gestation), at the end of the first trimester (at $\sim 17$ weeks) and during the third trimester (at $\sim 34$ weeks).

All 118 Dutch hospitals participated in the study and a total of 364 eligible women were reported to the study co-ordinator. In this paper data of the 289 women who gave birth to a live singleton infant without major congenital malformations at more than or equal to 28 weeks of gestation are shown.

The study had been approved by the Ethical Committee of University Medical Centre, Utrecht, The Netherlands. Participants gave written informed consent.

We recorded the following factors:

(i) Socio-demographics. Maternal age, race, smoking habits and parity.

(ii) Diabetes and treatment. Diabetes duration and long-term diabetic complications. This was based on reports from the women's internists. The complications were categorised and defined as follows: Retinopathy (as examined by an ophthalmologist): none, background, pre-proliferative or proliferative. Nephropathy: none, micro-albuminuria (30-300 mg/24 h or 20-200 mg/l at least once) or macroalbuminuria ( $\geq 300 \mathrm{mg} / 24 \mathrm{~h}$ or $\geq 200 \mathrm{mg} / \mathrm{l}$ at least once), assessed before pregnancy. Macrovascular complications: none, peripheral, and coronary. In this analysis diabetes was dichotomised into "uncomplicated diabetes" (absence of any stage of retinopathy, nephropathy or macrovascular complications) and "complicated diabetes" (presence of any stage of retinopathy, nephropathy or macrovascular complications). Diabetes treatment: continuous subcutaneous insulin infusion (CSII) or treatment with multiple ( $\geq 3$ /day) daily insulin injections (MIT). Insulin dosage and type of insulin during pregnancy. The insulin dosage $(\mathrm{U} / \mathrm{kg}$ ) during the first and third trimester was recorded and the difference in insulin dosage between the first and third trimester was calculated. Insulin type: human regular insulin or an insulin-analogue (insulin lispro).

(iii) Glycaemic control during pregnancy. Glycaemic control during pregnancy was assessed as follows: $\mathrm{HbA}_{1 \mathrm{c}}$-values during the first trimester $(n=257)$, second trimester $(n=257)$, and third trimester of pregnancy $(n=245)$ were collected from the local hospitals of the women. A standardisation procedure was adopted to adjust for variations between local $\mathrm{HbA}_{1 \mathrm{c}}$-assays [18]. Each local $\mathrm{HbA}_{1 \mathrm{c}}$-value was first standardised using the mean $\left(\mathrm{X}_{\mathrm{N}}\right)$ and standard deviation $\left(\mathrm{SD}_{\mathrm{N}}\right)$ for a local non-diabetic population. These scores $\left[\mathrm{Z}_{\mathrm{HbAlc}}=\left(\mathrm{HbA}_{1 \mathrm{c}}-\mathrm{X}_{\mathrm{N}}\right) / \mathrm{SD}_{\mathrm{N}}\right]$ were then transformed back to percent units using the mean $(5.0 \%)$ and standard deviation $(0.5 \%)$ of the Utrecht assay as follows: $\mathrm{HbA}_{1 \mathrm{c}}=0.5 \%\left(\mathrm{Z}_{\mathrm{HbAl}}\right)+5.0 \%$. Glycaemic control was divided into three categories: mean $\mathrm{HbA}_{1 \mathrm{c}}$ less than or equal to $6.0 \%$ ("excellent"), mean $\mathrm{HbA}_{1 \mathrm{c}} 6.1$ to $7.0 \%$ ("good") and mean $\mathrm{HbA}_{1 \mathrm{c}}$ greater than $7.0 \%$ ("not optimal"). The women were also asked to send a self-obtained capillary blood sample for $\mathrm{HbA}_{1 \mathrm{c}}$-measurement (HPLC, $\mathrm{HbA}_{1 \mathrm{c}}$ Capillary Collection System on Diamat, Biorad, Veenendaal, The Netherlands; normal reference value: 4.0-6.0\%) to a central laboratory early in pregnancy at about 10 weeks (Department of Clinical Chemistry and Haematology, Queen Beatrix Hospital Winterswijk, The Netherlands). Only results of samples that were mailed between 8 and 14 weeks gestation are included in the analyses $(n=205)$.

(iv) Severe hypoglycaemia during pregnancy. The occurrence of maternal severe hypoglycaemia $(\mathrm{SH})$ during the first trimester and third trimester of pregnancy (second and third questionnaire). Severe hypoglycaemia ( $\mathrm{SH}$ ) was defined as all episodes for which external help had been required including hypoglycaemic coma $[19,20]$. The proportion of women who were affected by at least one episode of SH during the first trimester and third trimester of pregnancy is reported.

(v) Co-morbidity and pregnancy related morbidity. Pre-existing hypertension was defined as a diastolic blood pressure greater than or equal to $90 \mathrm{~mm} \mathrm{Hg}$ in the first half of pregnancy. Pre-eclampsia was defined as a diastolic blood pressure greater than or equal to $90 \mathrm{~mm} \mathrm{Hg}$ on two occasions at least 4 hours apart and proteinuria greater than or equal to $300 \mathrm{mg}$ per 24 hours in the second half of pregnancy in a previously normotensive woman [21]. In patients with pre-existing hypertension, pre-eclampsia was diagnosed when a de novo proteinuria greater than or equal to $300 \mathrm{mg}$ per 24 hours occurred in the second half of pregnancy.

(vi) Weight and weight gain. BMI just before pregnancy and weight gain during pregnancy (minus infant birth weight).

(vii) Macrosomia. Birth weight was expressed as a birth weight percentile according to the official Dutch growth charts, as published in 1970 [22], and according to a growth chart based on the 1998 Dutch perinatal database (including 181000 deliveries). Details of the latter database are de- 
scribed elsewhere [23]. Macrosomia was defined as a birth weight greater than the 90th percentile corrected for gestational age, sex, parity and race. Severe macrosomia was defined as a birth weight greater than the 97.7 th percentile.

Statistical analysis. Statistical analysis was carried out using the statistical package SPSS (SPSS Release 10.0, SPSS, Chicago, Ill., USA). Data are shown as means with standard deviations or as percentages. We compared characteristics of the women who delivered a macrosomic infant to characteristics of the women with a normal birth weight infant. Continuous data were compared using the unpaired Student's $t$ test (two-tailed) and categorical data were compared using the chi square test. First, univariate analysis was due, in which odds ratios (OR) and $95 \%$ confidence intervals (CI) as well as $p$ values were calculated for both dichotomous and continuous variables. Subsequently, multiple logistic regression analysis was used to construct a prediction model for macrosomia. Stepwise selection of variables was applied, with a $p$ value of 0.15 as entry-criterion. The area under the receiver operating characteristic curve (ROC-curve), which can yield values from 0.5 (no predictive power) to 1 (perfect prediction), was computed to assess the predictive accuracy of the constructed logistic model.

\section{Results}

The mean $( \pm \mathrm{SD})$ birth weight of the 289 infants was $3566 \pm 711$ grams $(\mathrm{g})$ at $37.3 \pm 1.9$ weeks of gestation. Of these infants, $162(56.1 \%)$ were macrosomic, including $88(30.4 \%)$ severely, according to the official Dutch growth charts. These percentages were $48.8 \%$ and $26.6 \%$ respectively, according to the growth charts based on data collected in 1998 (Fig. 1). Of the infants, $73(25.3 \%)$ had a birth weight greater than $4000 \mathrm{~g}$ including 22 infants $(7.6 \%)$ with a birth weight greater than $4500 \mathrm{~g}$. The characteristics of the 289 women are shown in the first column of Table 1.

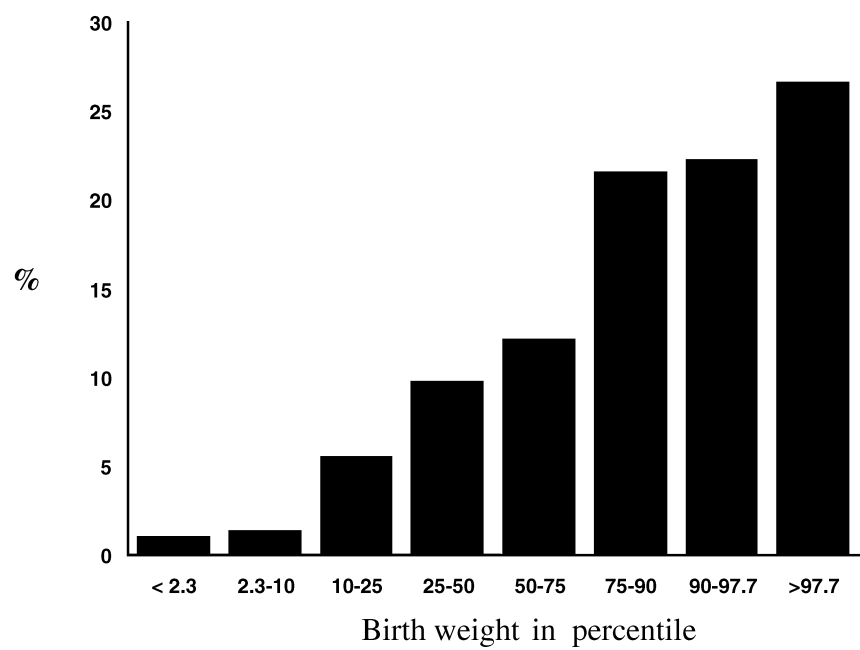

Fig. 1. Histogram showing the distribution among the birth weight percentile of the 289 infants of women with Type I diabetes, who became pregnant between 1st April 1999 and 1st April 2000. Reference data from the Dutch perinatal database of 1998 [23]
Demographics. Age, race and parity were not related to macrosomia. The proportion of non-smokers was higher among women with a macrosomic infant as compared to women with a non-macrosomic infant.

Diabetes and treatment. Virtually all women (98\%) were treated with intensive insulin treatment.

Women with and without macrosomic infants were not significantly different with respect to duration of diabetes, long-term diabetic complications, total daily insulin dosage $(\mathrm{U} / \mathrm{kg})$ in the first trimester and in the third trimester of pregnancy, increase in insulin dosage during pregnancy and use of insulin lispro. However, more women with a macrosomic infant were treated with CSII ( $45 \%$ vs $31 \% ; p=0.01$ ).

Glycaemic control during pregnancy. Second and third trimester $\mathrm{HbA}_{1 \mathrm{c}}$ and mean $\mathrm{HbA}_{1 \mathrm{c}}$ during pregnancy were higher in the women with a macrosomic infant. Glycaemic control was excellent (i.e. within the non-diabetic range) in $40 \%$, good in $44 \%$ and not optimal in $16 \%$ of the pregnancies. In $79 \%$ of the pregnancies with a macrosomic infant and in $89 \%$ of the pregnancies with a non-macrosomic infant glycaemic control was excellent or good $(p=0.03)$. Mean $\mathrm{HbA}_{1 \mathrm{c}}$ early in pregnancy measured in a central laboratory, was higher in the women with a macrosomic infant $(6.8 \pm 0.7 \%$ vs $6.5 \pm 0.7 \%$; $p=0.01)$.

Severe hypoglycaemia $(\mathrm{SH})$ during pregnancy. Fewer women with a macrosomic infant reported one or more episodes of SH during the first trimester and third trimester of pregnancy compared to the women with a non-macrosomic infant. Mean $\mathrm{HbA}_{1 \mathrm{c}}$ during pregnancy was higher in women without any SH than in women with $\mathrm{SH}$ during pregnancy (i.e. during first and/or third trimester $)(6.4 \pm 0.9 \%$ vs $6.0 \pm 0.7 \%$; $p=0.002$ ).

Co-morbidity and pregnancy related morbidity. There was no difference in pre-existing hypertension and pre-eclampsia between both groups.

Weight and weight gain. Pre-pregnancy BMI and weight gain during pregnancy were not different between both groups.

Multiple Logistic Regression Analysis of risk indicators predictive for macrosomia. In summary, univariate logistic regression analysis showed that non-smoking, CSII, second trimester and third trimester $\mathrm{HbA}_{1 \mathrm{c}}$, mean $\mathrm{HbA}_{1 \mathrm{c}}$ during pregnancy, absence of first and third trimester SH were associated with macrosomia. Multiple logistic regression analysis resulted in a predictive model with five variables: third trimester $\mathrm{HbA}_{1 \mathrm{c}}$ (OR[95\% CI]: (1.6[1.1-2.4]), absence of third trimester SH (3.0[1.2-7.3]), the use of insulin lispro (3.1[0.9-10.4]), weight gain during pregnancy 
Table 1. Comparison of characteristics between women with a macrosomic infant and women with a non-macrosomic infant in 289 Type I diabetic pregnancies

\begin{tabular}{|c|c|c|c|c|}
\hline & All $n=289$ & $\begin{array}{l}\text { Macrosomia } \\
n=141\end{array}$ & $\begin{array}{l}\text { No-macrosomia } \\
n=148\end{array}$ & $p$ value \\
\hline \multicolumn{5}{|l|}{ Socio-demographics } \\
\hline $\begin{array}{l}\text { Maternal age (years) } \\
\text { Race: Caucasian }(\%) \\
\text { Non-smoking }(\%) \\
\text { Nulliparous }(\%)\end{array}$ & $\begin{array}{l}30 \pm 4 \\
99 \\
88 \\
51\end{array}$ & $\begin{array}{l}30 \pm 4 \\
98 \\
92 \\
52\end{array}$ & $\begin{array}{l}30 \pm 4 \\
99 \\
84 \\
50\end{array}$ & $\begin{array}{l}0.75 \\
0.34 \\
0.04 \\
0.78\end{array}$ \\
\hline $\begin{array}{l}\text { Diabetes and treatment } \\
\text { Diabetes duration (years) } \\
\text { Complicated diabetes }(\%) \\
\text { CSII (\%) } \\
\text { Use of insulin lispro }(\%) \\
\text { Insulin dosage/24 h first trimester }(\mathrm{U} / \mathrm{kg}) \\
\text { Insulin dosage/24 h third trimester }(\mathrm{U} / \mathrm{kg}) \\
\text { Increase insulin dosage first-third trimester (U/kg) }\end{array}$ & $\begin{array}{l}13 \pm 8 \\
26 \\
38 \\
11 \\
0.74 \pm 0.28 \\
1.0 \pm 0.41 \\
0.29 \pm 0.37\end{array}$ & $\begin{array}{l}12 \pm 8 \\
24 \\
45 \\
15 \\
0.74 \pm 0.26 \\
0.98 \pm 0.38 \\
0.25 \pm 0.34\end{array}$ & $\begin{array}{l}13 \pm 7 \\
27 \\
31 \\
8 \\
0.74 \pm 0.30 \\
1.1 \pm 0.44 \\
0.32 \pm 0.40\end{array}$ & $\begin{array}{l}0.52 \\
0.57 \\
0.01 \\
0.07 \\
0.92 \\
0.21 \\
0.15\end{array}$ \\
\hline 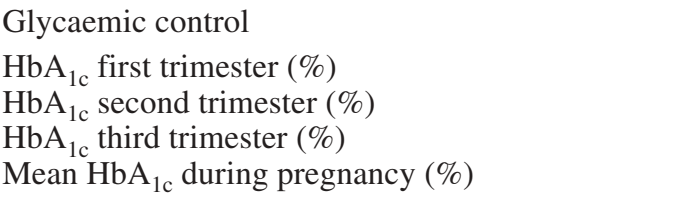 & $\begin{array}{l}6.5 \pm 1.0 \\
6.0 \pm 0.9 \\
6.2 \pm 1.1 \\
6.2 \pm 0.9\end{array}$ & $\begin{array}{l}6.7 \pm 1.1 \\
6.1 \pm 1.0 \\
6.5 \pm 1.1 \\
6.4 \pm 1.0\end{array}$ & $\begin{array}{l}6.4 \pm 1.0 \\
5.8 \pm 0.8 \\
6.0 \pm 1.1 \\
6.1 \pm 0.9\end{array}$ & $\begin{array}{l}0.07 \\
0.007 \\
0.0001 \\
0.005\end{array}$ \\
\hline $\begin{array}{l}\text { Severe Hypoglycaemia }(\mathrm{SH}) \\
\% \text { of women with first trimester } \mathrm{SH} \\
\% \text { of women with third trimester } \mathrm{SH}\end{array}$ & $\begin{array}{l}41 \\
16\end{array}$ & $\begin{array}{l}33 \\
11\end{array}$ & $\begin{array}{l}48 \\
21\end{array}$ & $\begin{array}{l}0.01 \\
0.04\end{array}$ \\
\hline $\begin{array}{l}\text { Co-morbidity and pregnancy related morbidity } \\
\text { Essential hypertension }(\%) \\
\text { Pre-eclampsia }(\%)\end{array}$ & $\begin{array}{r}4 \\
12\end{array}$ & $\begin{array}{r}3 \\
10\end{array}$ & $\begin{array}{r}5 \\
14\end{array}$ & $\begin{array}{l}0.27 \\
0.27\end{array}$ \\
\hline $\begin{array}{l}\text { Weight and weight gain } \\
\text { Pre-pregnancy BMI }\left(\mathrm{kg} / \mathrm{m}^{2}\right) \\
\text { Weight gain during pregnancy }(\mathrm{kg})\end{array}$ & $\begin{array}{r}25.0 \pm 3.6 \\
8.6 \pm 5.0\end{array}$ & $\begin{array}{r}25.1 \pm 3.5 \\
8.9 \pm 4.6\end{array}$ & $\begin{array}{r}24.8 \pm 3.7 \\
8.2 \pm 5.3\end{array}$ & $\begin{array}{l}0.53 \\
0.28\end{array}$ \\
\hline
\end{tabular}

(1.1[1.0-1.2]) and non-smoking (2.8[0.9-9.3]). The area under the ROC-curve of this model was 0.71 . Third trimester $\mathrm{HbA}_{1 \mathrm{c}}$ was the first term to enter the model, explaining $4.7 \%$ of the variance of macrosomia. Additionally absence of third trimester $\mathrm{SH}$ explained $2.9 \%$, insulin lispro $2.6 \%$, weight gain during pregnancy $1.6 \%$ and non-smoking $1.5 \%$. Secondly, third trimester $\mathrm{HbA}_{1 \mathrm{c}}$ was dichotomised into less than or equal to $6.5 \%$ and greater than $6.5 \%$, resulting in a predictive model with third trimester $\mathrm{HbA}_{1 \mathrm{c}}$ greater than $6.5 \%$ (2.7[1.3-5.4]), absence of third trimester $\mathrm{SH}$ (3.1[1.3-7.6]), the use of insulin lispro (3.0[0.9-10.1]), weight gain during pregnancy $(1.1[1.0-1.2])$ and nonsmoking $(2.5[0.8-7.9])$. The area under the ROC-curve of this model was 0.68 .

\section{Discussion}

This study shows that in a non-selected group of women with Type I diabetes mellitus, macrosomia occurred in more than half $(56.1 \%)$ or almost half of them $(48.8 \%)$, depending on the reference growth chart used. Since population birth weight has increased over the years, the use of an up-to-date chart is essential. The incidence reported in our study is in concordance with the incidences of (severe) macrosomia reported from other Northern European countries in the last decade. In Sweden (1991-1996) more than $33 \%$ of the infants from Type I diabetic mothers were severe macrosomic [1], in Denmark (1993-1999) $27.6 \%$ of the infants were macrosomic (birth weight $\geq$ $4000 \mathrm{~g})$ [16] and from Finland a marked increase in the number of macrosomic infants (to 34\%) was reported [17]. In Type I diabetic pregnancy, foetal macrosomia is still a significant, and could even be a rising problem, despite modern therapy (i.e. intensive insulin treatment).

We found a high incidence of macrosomia despite overall good glycaemic control, as assessed by $\mathrm{HbA}_{1 \mathrm{c}}$, in most of the women. Third trimester $\mathrm{HbA}_{1 \mathrm{c}}$ was an independent risk indicator for macrosomia, which is in agreement with other studies $[4,5]$. A third trimester $\mathrm{HbA}_{1 \mathrm{c}}$ greater than $6.5 \%$ was associated with a twofold to threefold increase in macrosomia. However, although third trimester $\mathrm{HbA}_{1 \mathrm{c}}$ was the most powerful 
predictor of macrosomia that we detected, its predictive capacity was only weak (explained variance $<5 \%$ ). This implies that glycaemic control measured by conventional methods (i.e. $\mathrm{HbA}_{1 \mathrm{c}}$ ) does not explain the high incidence of macrosomia. Several phenomena could contribute to the explanation of this.

Firstly, glucose variability and post-prandial hyperglycaemic episodes, which are not reflected in the $\mathrm{HbA}_{1 \mathrm{c}}$-value, can be involved. This means that more detailed assessments of glycaemic control, such as continuous subcutaneous glucose measurement techniques, are needed to monitor women with Type I diabetes during pregnancy. The advent of continuous glucose monitoring has recently been applied in pregnant women with gestational diabetes [24]. This study showed that the continuous glucose monitoring system (CGMS) detects post-prandial glucose increases that were not detected by conventional intermittent self-monitoring of blood glucose (SMBG). Perhaps the statement "macrosomia despite normoglycaemia" should rather say "macrosomia because of undetected (post-prandial) hyperglycaemia" [25]. The application of the CGMS enables more tailored insulin therapy. Therefore, using CGMS might be helpful in optimising glycaemic control and in reducing the incidence of macrosomia in Type I diabetic pregnancy.

Secondly, observations in foetal sheep showed that continually high values of maternal glucose did not stimulate continuing foetal hyperinsulinism, but that "pulsatile" hyperglycaemia did [26]. So, intermittent hyperglycaemia (usually with normal $\mathrm{HbA}_{1 \mathrm{c}}$ ) could be more important than chronic hyperglycaemia (usually with higher $\left(\mathrm{HbA}_{1 \mathrm{c}}\right)$ in causing accelerated foetal growth [27].

Thirdly, poor glycaemic control early in pregnancy has been associated with congenital malformations and early growth delay [28]. Nowadays, most of the diabetic women enter their pregnancy well-controlled, which was also the case in our cohort [29]. We could speculate that improved early glycaemic control favours placental development and subsequently foetal growth.

Several studies have reported an increased incidence of severe hypoglycaemia $(\mathrm{SH})$ during pregnancy, with the highest rate in the first trimester [30, 31, 32]. The main reason for this high rate is striving for tight glycaemic control (i.e. $\mathrm{HbA}_{1 \mathrm{c}} \leq 6.5 \%$ ) [32]. In our study, absence of third trimester $\mathrm{SH}$ increased the risk of macrosomia. Other studies also have reported non-significant higher incidences of macrosomia in women not affected by SH during pregnancy (38\% vs $20 \%$ and $48 \%$ vs $31 \%$; both $p>0.05$ ) [30, 31]. Since the number of patients in those studies was much lower $(\approx 85$ women), the power to detect a statistically significant association between the occurrence of $\mathrm{SH}$ and a decreased macrosomia rate could have been too small. Mean $\mathrm{HbA}_{1 \mathrm{c}}$ during pregnancy (i.e. overall glycaemic control) was higher in women without any $\mathrm{SH}$ than in women with $\mathrm{SH}$ during pregnancy. This might explain the increased risk of macrosomia in these women. Animal studies have shown that experimentally induced chronic maternal hyperinsulinaemia and hypoglycaemia during pregnancy resulted in foetal hypoglycaemia, hypo-insulinaemia and intra-uterine growth retardation [33].

Studies regarding the use of insulin lispro and infant birth weight in Type I diabetic pregnancies are scarce. A study observed a trend towards less macrosomia [34], and another showed no significant difference in the prevalence of macrosomia [35]. In our study, $11 \%$ of the women were treated with insulin lispro. Surprisingly, the use of insulin lispro was associated with an increased risk of macrosomia. Possibly, the women who were treated with insulin were a selected group of women, i.e. especially those women with difficulties in optimising their glycaemic control. In these women first, second and third trimester $\mathrm{HbA}_{1 \mathrm{c}}$, and mean $\mathrm{HbA}_{1 \mathrm{c}}$ during pregnancy were higher, but the differences were not statistically significant.

Weight gain during pregnancy and non-smoking were also independent risk indicators for macrosomia. This observation is in agreement with earlier findings in diabetic and non-diabetic populations [36, 37].

The area under the curve of 0.71 for the prediction of macrosomia indicated that the capacity of the five indicators to predict macrosomia was very limited. So, we are not able to explain the extremely high incidence of macrosomia in our study with these variables.

In conclusion, despite apparent good glycaemic control during pregnancy, the incidence of foetal macrosomia in this non-selected prospective nationwide cohort of 289 Type I diabetic women was very high. A higher third trimester $\mathrm{HbA}_{1 \mathrm{c}}(>6.5 \%)$, absence of third trimester $\mathrm{SH}$, the use of insulin lispro, weight gain during pregnancy and non-smoking were risk indicators predictive for the occurrence of macrosomia. Third trimester $\mathrm{HbA}_{1 \mathrm{c}}$ was the most powerful predictor, but its predictive capacity was weak. Thus, future research should focus on new, more detailed glucose monitoring techniques (such as CGMS) as well as alternative factors to reduce macrosomia.

Acknowledgements. We thank all gynaecologists, internists, and diabetes nurse educators in the Netherlands for including their patients in this nationwide study. We thank PRISMANT Health Care Information who gave us permission to use their perinatal register of 1998 and TNO Prevention and Health for their statistical analysis of this register. Novo Nordisk Farma BV, Alphen aan De Rijn, The Netherlands, financially supported this study.

\section{References}

1. Djerf P, Hanson U (2000) Perinatal complications in large for gestational age (LGA) infants compared to non-LGA infants of type-1-diabetic mothers. 32nd Annual Meeting Diabetic Pregnancy Study Group (DPSG) of the EASD, Galilee (Abstract p 38) 
2. Nordic Medico-Statistical Committee (NOMESCO) (1993) Births and infants mortality in the nordic countries. NOMESCO, Copenhagen, $\mathrm{p} 39$

3. Lewis DF, Edwards MS, Asrat T et al. (1998) Can shoulder dystocia be predicted? Preconceptive and prenatal factors. J Reprod Med 43:654-658

4. Berk MA, Mimouni F, Miodovnik M, Hertzberg V, Valuck $\mathrm{J}$ (1989) Macrosomia in infants of insulin-dependent diabetic mothers. Pediatrics 86:1029-1034

5. Small M, Cameron A, Lunan CB, MacCuish AC (1987) Macrosomia in pregnancy complicated by insulin-dependent diabetes mellitus. Diabetes Care 10:594-599

6. Gutgesell HP, Speer ME, Rosenberg HS (1980) Characterization of the cardiomyopathy in infants of diabetic mothers. Circulation 61:441-450

7. Pettitt DJ, Knowler WC (1998) Long-term effects of the intrauterine environment, birth weight and breast-feeding in Pima Indians. Diabetes Care 21 [Suppl 2]:B138-B141

8. Silverman BL, Rizzo T, Green OC et al. (1991). Long-term prospective evaluation of offspring of diabetic mothers. Diabetes 40 [Suppl 2]:121-125

9. Vohr BR, Lipsitt LP, Oh W (1980) Somatic growth of the children of diabetic mothers with reference to birth size. J Pediatr 97:196-199

10. Langer O (2000) Fetal macrosomia: etiologic factors. Clin Obstet Gynecol 43:283-297

11. Gold AE, Reilly R, Little J, Walker JD (1998) The effect of glycemic control in the pre-conception period and early pregnancy on birth weight in women with IDDM. Diabetes Care 21:535-538

12. Johnstone FD, Mao JH, Steel JM, Prescott RJ, Hume R (2000) Factors affecting fetal weight distribution in women with type 1 diabetes. Br J Obstet Gynaecol 107:1001-1006

13. Jovanovic-Peterson L, Peterson CM, Reed GF et al. (1991) Maternal postprandial glucose levels and infant birth weight: The diabetes in early pregnancy study. Am J Obstet Gynecol 164:103-111

14. Peck RW, Price DE, Lang GD, Macvicar J, Hearnshaw JR (1991) Birth weight of babies born to mothers with type 1 diabetes: is it related to blood glucose control in the first trimester? Diabet Med 8:258-262

15. Visser GHA, Ballegooie E van, Sluitier WJ (1984) Macrosomy despite well-controlled diabetic pregnancy. Lancet i: $284-285$

16. Damm P, Jensen DM, Beck-Nielsen H et al. (2001) Outcomes in pregnancies complicated by type 1 diabetes. A population based Danish study. 33rd Annual Meeting Diabetic Pregnancy Study Group (DPSG) of the EASD, Oxford (Abstract p 39)

17. Teramo K (1998) Sikiön makrosomia on yhä äidin diabeteksen suuri ongelma. Duodecim 114:73-79

18. Tamborlane WV, Champion MC, Rizza RA, Service FJ, Bergenstal RM for the KROC collaborative study group (1985) Observations on control of glycaemia with conventional insulin therapy or continuous subcutaneaous insulin infusion. Diabetes 34 [Suppl 3]:22-26

19. Tattersall RB (1999) Frequency, causes and treatment of hypoglycaemia. In: Frier BM, Fisher BM (eds) Hypoglycaemia in clinical diabetes. Wiley, Chichester, pp 55-87

20. DCCT group (1998) The effect of intensive treatment of diabetes on the development and progression of long-term complications in insulin-dependent diabetes mellitus. The Diabetes Control and Complications Trial Research Group. N Engl J Med 329:977-986
21. Davey DA, Macgillivray I (1988) The classification and definition of hypertension disorders in pregnancy. Am J Obstet Gynecol 158:892-898

22. Kloosterman GJ (1970) On intra-uterine growth. Int J Obstet Gynecol 8:895-912

23. Anthony S, Pal-de Bruin KM van der, Graafmans WC et al. (2001). The reliability of perinatal and neonatal mortality rates: differential under-reporting in linked professional registers vs Dutch civil registers. Paediatr Perinat Epidemiol 15:306-314

24. Jovanovic L (2000) The role of continuous glucose monitoring in gestational diabetes. Diabetes Technol Ther 2 [Suppl 1]:67-71

25. Jovanovic L (2001) What is so bad about a big baby? Diabetes Care 24:1317-1318

26. Carver TD, Anderson SM, Aldoretta PW, Hay WW (1996) Effect of low-level basal plus marked "pulsatile" hyperglycaemia on insulin secretion in fetal sheep. Am J Physiol 271:E865-E871

27. Kyne-Grzebalski D, Wood L, Marshall SM, Taylor R (1999) Episodic hyperglycaemia in pregnant women with well-controlled Type 1 diabetes mellitus: a major potential factor underlying macrosomia. Diabet Med 16:702-706

28. Molsted-Pedersen L, Pedersen JF (1994) Type-1 diabetes, congenital malformations and early growth delay. In: Visser GHA, Bruinse HW (eds) Diabetes and pregnancy [Diabetes en zwangerschap], Grafitel-Veldwijk, Vorden, pp 31-35

29. Evers IM, Valk HW de, Visser GHA (2001) A nation-wide prospective study on the outcome of pregnancies in women with type 1 diabetes mellitus; do planned pregnancies result in better pregnancy outcome? Diabetologia 44 [Suppl 1]:A42 (Abstract)

30. Kimmerle R, Heineman L, Delecki A, Berger M (1992) Severe hypoglycaemia incidence and predisposing factors in 85 pregnancies of type 1 diabetic women. Diabetes Care 15:1034-1037

31. Rayburn W, Piehl E, Jacober S, Schork A, Ploughman L (1986) Severe hypoglycaemia during pregnancy: its frequency and predisposing factors in diabetic women. Int J Gynaecol Obstet 24:263-268

32. Evers IM, Braak EWMT ter, Valk HW de, Schoot B van der, Janssen N, Visser GHA (2002) Risk indicators predictive for severe hypoglycemia during the first trimester of type 1 diabetic pregnancy. Diabetes Care 25:554-559

33. DiGiacomo JE, Hay WW Jr (1990) Fetal glucose metabolism and oxygen consumption during sustained hypoglycaemia. Metabolism 39:193-202

34. Ozcan T, Karne A, Murphy J, Nickless N, Magriples U, Jones DC (2001) Does lispro improve blood glucose control and birth weight? Obstet Gynecol 97 [4 Suppl1]:S41

35. Garg SK, Anil S, Gottlieb P, MacKenzie T, Jackson WE (2001) Longer gestation period and better glycaemic control with insulin lispro treated pregnancies in type 1 diabetes. Diabetologia 44 [Suppl 1]:A245 (Abstract)

36. Caulfield LE, Harris SB, Whalen EA, Sugamori ME (1998) Maternal nutritional status, diabetes and risk of macrosomia among Native Canadian women. Early Hum Dev 50:293-303

37. Madsen H, Ditzel J (1991) The influence of maternal weight, smoking, vascular complications and glucose regulation on the birth weight of infants of type 1 diabetic women. Eur J Obstet Gynecol Reprod Biol 39:175-179 